\title{
Determining if Exhaust Emission From Light Duty Vehicle During Acceleration on The Basis of On-Road Measurements and Simulations
}

\author{
Mateusz Nowak', Michalina Kamińska', Natalia Szymlet ${ }^{1 *}$ \\ 1 Faculty of Civil and Transport Engineering, Poznan University of Technology, pl. Marii Skłodowskiej-Curie 5, \\ 60-965 Poznań, Poland \\ * Corresponding author's e-mail: natalia.r.szymlet@doctorate.put.poznan.pl
}

\begin{abstract}
Vehicle exhaust emissions depend on multiple factors, such as the emission norm, driving parameters (speed, acceleration) or the technical condition of the vehicle. These driving parameters may often depend on the condition of the road infrastructure and other factors influencing road conditions. The article attempted to assess the emissivity during acceleration of a vehicle powered by a compression ignition engine. Mapping the actual values is possible with the use of exhaust emission measurement equipment that operates under the actual operating conditions of a vehicle. Recently, an increase in the use of simulation methods in research of this type has been observed. The authors decided to check the suitability of using road traffic simulation software to estimate the $\mathrm{CO}_{2}$ emissions during vehicle acceleration. The obtained results are promising, because in terms of the emissions of the analyzed exhaust gas component, the simulation results differed from the results obtained during measurements with the use of Portable Emissions Measurement System (PEMS) equipment by less than $\pm 20 \%$.
\end{abstract}

Keywords: air pollution, $\mathrm{CO}_{2}$ emission, real driving emissions, PEMS, simulations

\section{INTRODUCTION}

The latest figures from the European Parliament show that almost $30 \%$ of total $\mathrm{CO}_{2}$ emissions are generated by the transport sector [www. europarl.europa.eu]. In addition to harmful carbon dioxide, which contributes to the deepening of the greenhouse effect, motor vehicles generate toxic nitrogen oxides, carbon oxides, hydrocarbons and particulate matter. Moreover, the condition of infrastructure and road conditions (pavement condition, weather conditions, road congestion) also has a significant impact on the emission of toxic compounds from vehicles. The analysis of the data prepared and made available by the General Directorate for National Roads and Motorways (Polish acronym: GDKiA) shows that most of the problems relevant to this issue are related to road works (Fig. 1).

These are long-term actions causing disruptions and drivers are forced to use detours or neighboring roads to meet their transport needs, thus causing the travel process to be less smooth and uniform as well as generating the so-called bottlenecks. As indicated by one of the authors' previous works [Szymlet, Lijewski and Kurc 2020], avoiding congestion has a positive impact on time savings (the journey was shortened by 9 minutes) and ecological savings $(27 \%, 32 \%$, $15 \%$ reduction of $\mathrm{CO}_{2}, \mathrm{HC}$ and $\mathrm{CO}$ road emissions was obtained, respectively).

The current trend worldwide is motor vehicles testing under the actual operating conditions, performed in order to obtain complete information on the real emission of exhaust gas components and the actual engine operating parameters [Merkisz et al. 2012, 2014, Rymaniak et al. 2019, Rymaniak 2017]. Using this testing method, it is possible to obtain the most reliable emission results that are impossible to achieve in laboratory tests. This type of research with the use of mobile PEMS equipment (Portable Emission 


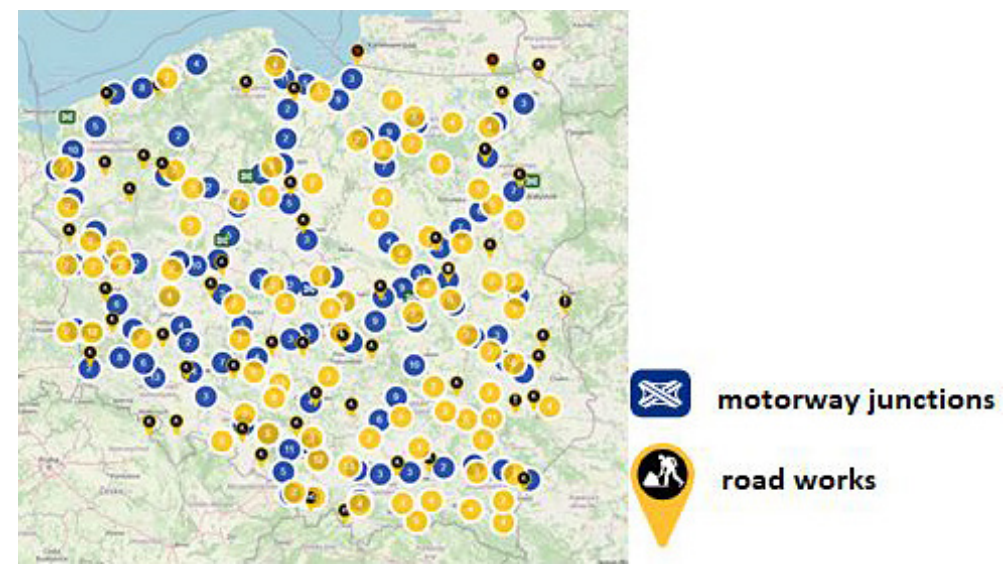

Figure 1. Map of Poland with marked road difficulties and road junctions as of July 21, 2021. [www.drogi.gddkia.gov.pl]

Measurement System) allows recording exhaust emission data for toxic compounds for the road conditions that exist at any given moment during a drive test. The disadvantage of such tests is, unfortunately, their high cost, related to the sophisticated equipment needed, adaptation of the vehicle to measurements, and the time-consuming nature of the test drives under the actual operating conditions. Therefore, in order to save time and resources scientists choose to use vehicle, engine or combustion process simulation software instead. The PTV Vissim program is the world standard in the field of traffic and transport planning and the estimation of toxic exhaust emissions. It allows simulating realistically complex interactions at the micro level, detailed modeling of demand, supply and road driving behavior. It also enables an overview of the traffic flow and its effects on many defined scenarios by modeling various geometries of both standard and more complex intersections. A literature review indicates that many researchers use this software to simulate different aspects, such as the environmental impact of vehicles [Abou-Senna 2013, Csikós and Varga 2012, Nowak and Pielecha 2017]. Another of the authors works which used the aforementioned simulation software includes an analysis of the impact of rail traffic on road driving conditions (road-rail crossings) [Nowak et al. 2019]. The article compares the distance traveled and its duration for two different scenarios (closed and open road-rail crossing) with the use of simulation software. Other literature items concerned, among others, a comparative analysis of various systems for microscopic traffic simulation [Maciejewski 2010], calibration of the simulation model in terms of vehicle acceleration [Madi
2016] or the use of the PTV Vissim software to assess the reduction of the ecological impact of passenger cars while increasing the share of electric vehicles using the city of Rzeszów as an example [Mądziel et al. 2021].

The most important aspect of the software is that the simulation can reproduce the variability of the vehicle that can be found in the real world. Therefore, the first part of the research, which is the subject of this study, was based on measurements under the actual operating conditions. In the further part, however, modern microscopic road simulation software PTV Vissim 5.40 was employed, which uses the software simulation to determine the toxic exhaust emissions.

\section{METHODOLOGY}

In order to perform the research described in the article, a light commercial vehicle equipped with a compression-ignition internal combustion engine was used (Table 1). The engine with a displacement of $1.3 \mathrm{dm}^{3}$ had a maximum power of $66 \mathrm{~kW}$ at 4,000 rpm and a maximum torque of $200 \mathrm{Nm}$ at $1,500 \mathrm{rpm}$. The vehicle was equipped with Diesel Oxidation Catalyst (DOC) and Diesel Particulate Filter (DPF) and, according to the manufacturer's data, met the Euro 4 exhaust emission norm.

The tests under the actual operating conditions were carried out using the Axion R/S+ mobile Micro Portable Emission Measurement System (PEMS) analyzer manufactured by Global MRV. The device can be used to measure the concentration of harmful gaseous exhaust compounds. Carbon dioxide $\left(\mathrm{CO}_{2}\right)$, carbon monoxide 
Table 1. Test engine technical data

\begin{tabular}{|l|c|}
\hline \multicolumn{1}{|c|}{ Engine type } & Diesel \\
\hline $\begin{array}{l}\text { Number and arrangement of } \\
\text { cylinders, number of valves }\end{array}$ & $\begin{array}{c}4 \text { cylinders, in-line, } \\
16 \text { valves per cylinder }\end{array}$ \\
\hline Displacement & $1.3 \mathrm{dm}^{3}$ \\
\hline Maximum power & $66 \mathrm{~kW} / 4000 \mathrm{rpm}$ \\
\hline Maximum torque & $200 \mathrm{Nm} / 1500 \mathrm{rpm}$ \\
\hline Compression ratio & $17: 1$ \\
\hline Fuel injection & Common Rail \\
\hline Type of charger & VGT, intercooler \\
\hline $\begin{array}{l}\text { Emission reduction and } \\
\text { aftertreatment systems }\end{array}$ & DOC, DPF \\
\hline
\end{tabular}

(CO) and hydrocarbons (HC) are measured using the Non-Dispersive Infra-Red (NDIR) analyzer, while nitrogen oxides (NO) and oxygen $\left(\mathrm{O}_{2}\right)$ are measured with an electrochemical analyzer. The apparatus also allows for measuring the concentration of particulate matter (PM) using the Laser Scatter method, in which the speed of particle movement is measured (taking into account the relative values assigned to PM10 size particles). The device is additionally equipped with a weather station, a Global Positioning System (GPS) as well as a module for recording the data from the on-board vehicle diagnostics system. The OBD data is acquired and recorded at a frequency of 1 $\mathrm{Hz}$ [www.globalmrv.com].

The vehicle acceleration simulations were carried out using the PTV Vissim software, dedicated to simulating the movement of vehicles on a microscopic scale. In addition to the traffic generated by cars and trucks, this software was also able to include pedestrian traffic and public transport vehicles (buses and trams) in the simulated traffic network. Correct reproduction of close-toreal vehicle movement requires proper calibration of the model. In the presented case, when only the acceleration of the vehicle was analyzed without simulating any further travel, the model was adjusted in terms of the acceleration profile characteristic. The exhaust emission characteristics implemented in the software have not been modified in any way. The authors chose only from the emission categories available for selection in the software; a vehicle powered by a compressionignition engine that meets the Euro 4 emission standard was selected.

The process of vehicle acceleration can be reproduced on any section of the road, but in the presented case it was a fragment of the Kórnicka Street in the Poznan agglomeration with traffic lights present, which was reproduced with a slight curvature (Fig. 2). The acceleration of the vehicles that stopped at a red light was analyzed.

\section{RESULT AND ANALYSIS}

The article presents two acceleration profile examples obtained during the tests under the actual driving conditions. The first measurement was made during the acceleration of the vehicle from $0 \mathrm{~km} / \mathrm{h}$ to $56 \mathrm{~km} / \mathrm{h}$, and the second one from $0 \mathrm{~km} / \mathrm{h}$ to $43 \mathrm{~km} / \mathrm{h}$. The $\mathrm{R}^{2}$ coefficient, which is a measure of the quality of the best fit line for both tests, was 0.95 and 0.93 respectively, which means that the vehicle speed increased almost linearly. In terms of acceleration, the characteristics were similar for both profiles. For the first profile (Fig. 3). from $0.03 \mathrm{~m} / \mathrm{s}^{2}$ to $1.67 \mathrm{~m} / \mathrm{s}^{2}$, while in the case of the second profile (Fig. 4) from $0.03 \mathrm{~m} / \mathrm{s}^{2}$ to $1.1 \mathrm{~m} / \mathrm{s}^{2}$. Both profiles are characterized by the highest acceleration values in the initial stage of vehicle acceleration.

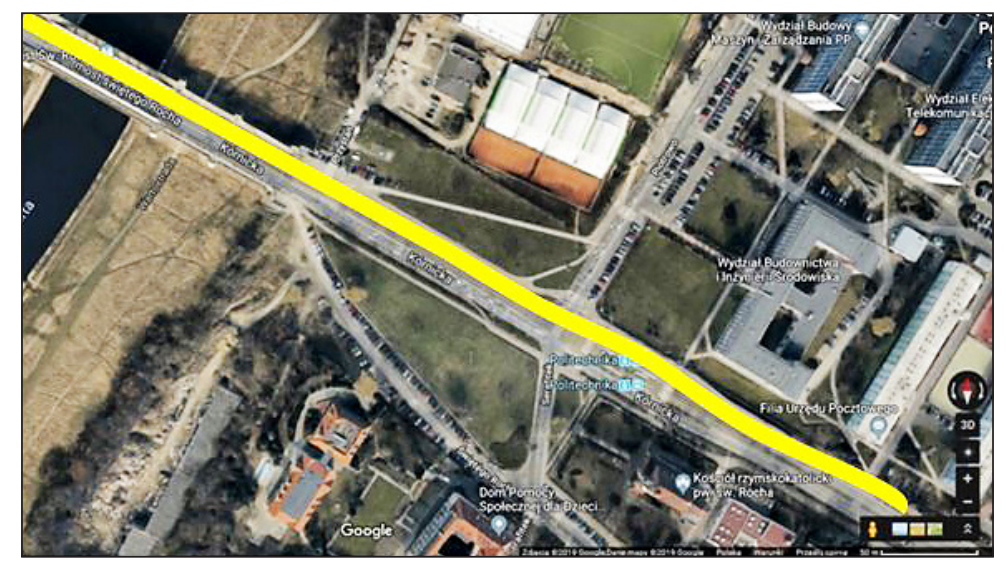

Fig. 2. Fragment of the Kórnicka street in Poznań, used for the vehicle acceleration simulation [www.gpsvisualizer.com] 


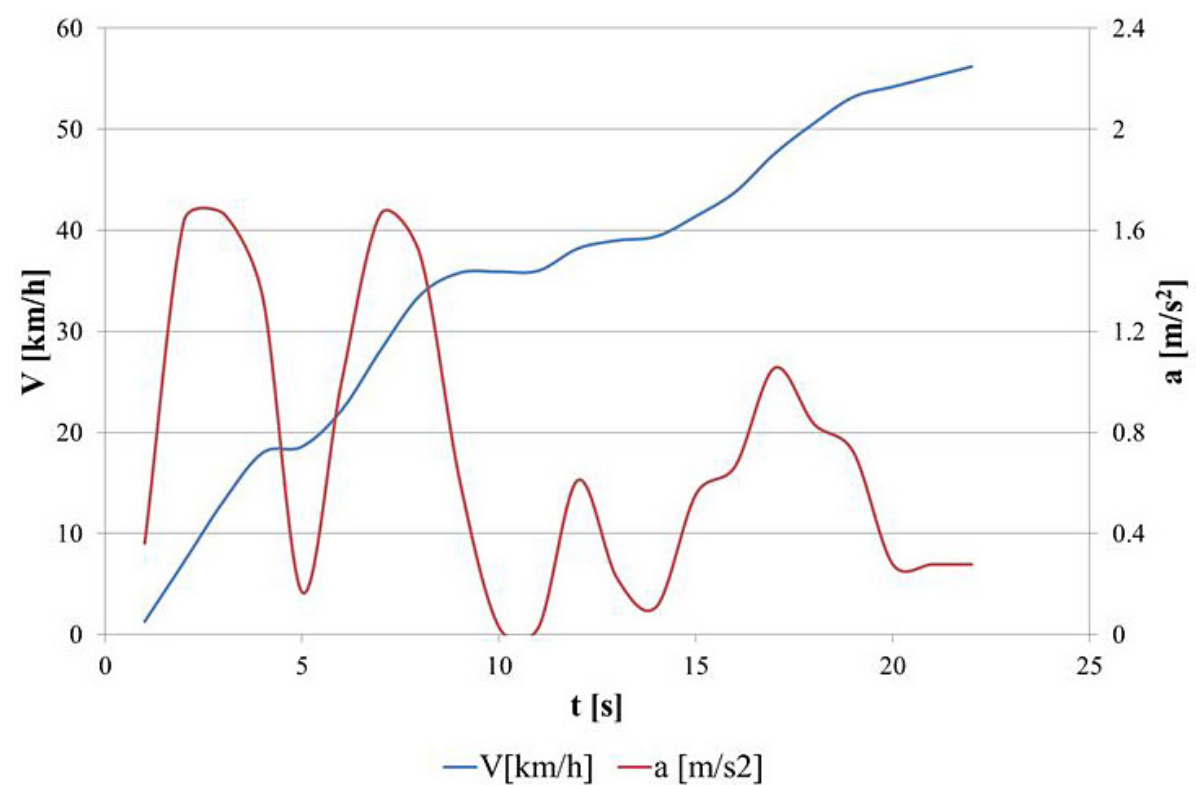

Fig. 3. Vehicle acceleration curve, profile I

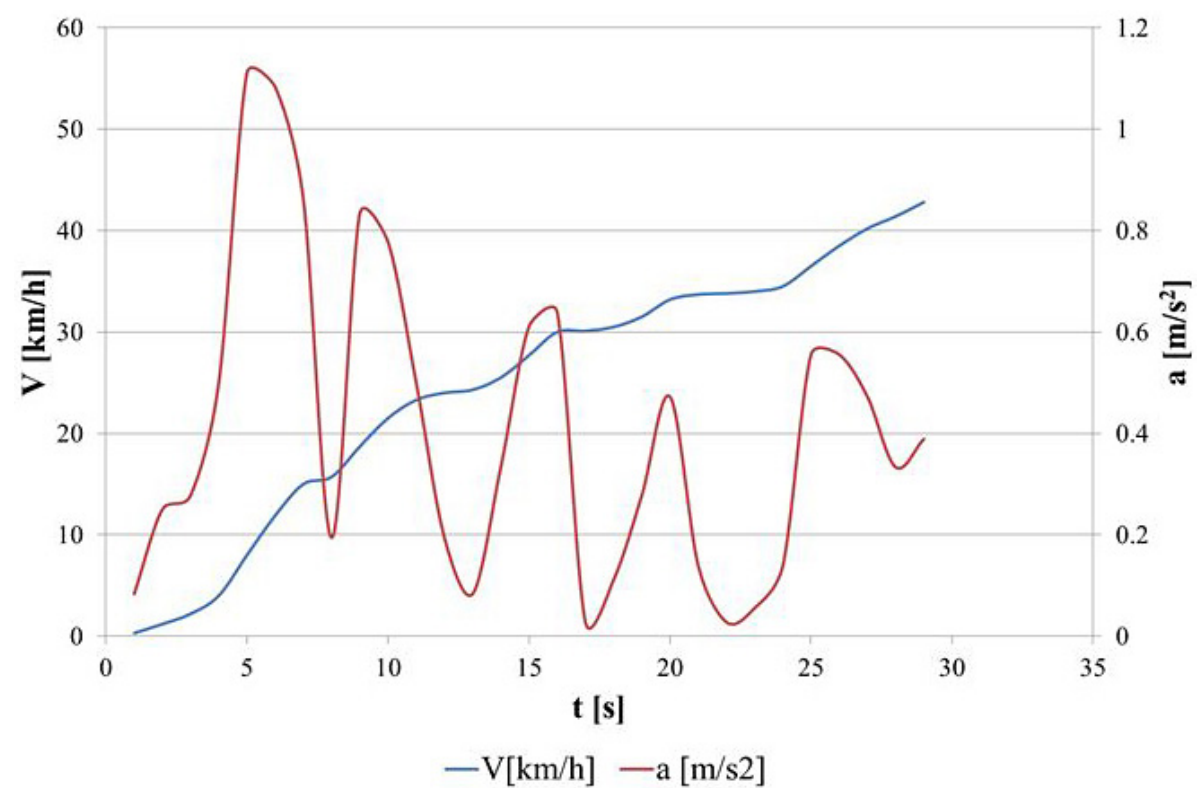

Fig. 4. Vehicle acceleration curve, profile II

The analysis of the vehicle performance indicators was extended through the addition of exhaust emission values of harmful exhaust gas compounds (Figs. 5 and 6). For the first drive profile, the values of all pollutants increased in line with the increasing acceleration values. The maximum values of $\mathrm{CO}_{2}(5.8 \mathrm{~g} / \mathrm{s}), \mathrm{CO}(5.2 \mathrm{mg} / \mathrm{s}), \mathrm{HC}$ $(2.4 \mathrm{mg} / \mathrm{s}), \mathrm{NO}_{\mathrm{x}}(34.9 \mathrm{mg} / \mathrm{s})$ and $\mathrm{PM}(1.7 \mathrm{mg} / \mathrm{s})$ were recorded in the 8 th second of the acceleration measurement, during which the vehicle acceleration was measured at $1.5 \mathrm{~m} / \mathrm{s}^{2}$. The sum of these emitted compounds was: $57.5 \mathrm{~g} / \mathrm{s}$ of carbon dioxide, $50.7 \mathrm{mg} / \mathrm{s}$ of carbon oxide, $22.7 \mathrm{mg} / \mathrm{s}$ of hydrocarbons, $285 \mathrm{mg} / \mathrm{s}$ of nitrogen oxides and $7.3 \mathrm{mg} / \mathrm{s}$ of particulate matter.

For the second drive profile, there was no direct observable relation between the emissions of harmful exhaust gas compounds and the vehicle acceleration value. The maximum emission values of $\mathrm{CO}_{2}(3.2 \mathrm{~g} / \mathrm{s}), \mathrm{HC}(0.52 \mathrm{mg} / \mathrm{s})$ and $\mathrm{PM}(0.33 \mathrm{mg} / \mathrm{s})$ were observed in the 16 th second of the acceleration measurement (at $\left.0.5 \mathrm{~m} / \mathrm{s}^{2}\right)$. For CO $(0.7 \mathrm{mg} / \mathrm{s})$, the highest value occurred at 20 seconds into the drive (acceleration value of $0.3 \mathrm{~m} / \mathrm{s}^{2}$ ) and the local maximum for $\mathrm{NO}_{\mathrm{x}}(7.3 \mathrm{mg} / \mathrm{s})$ was found for the 7 th second 


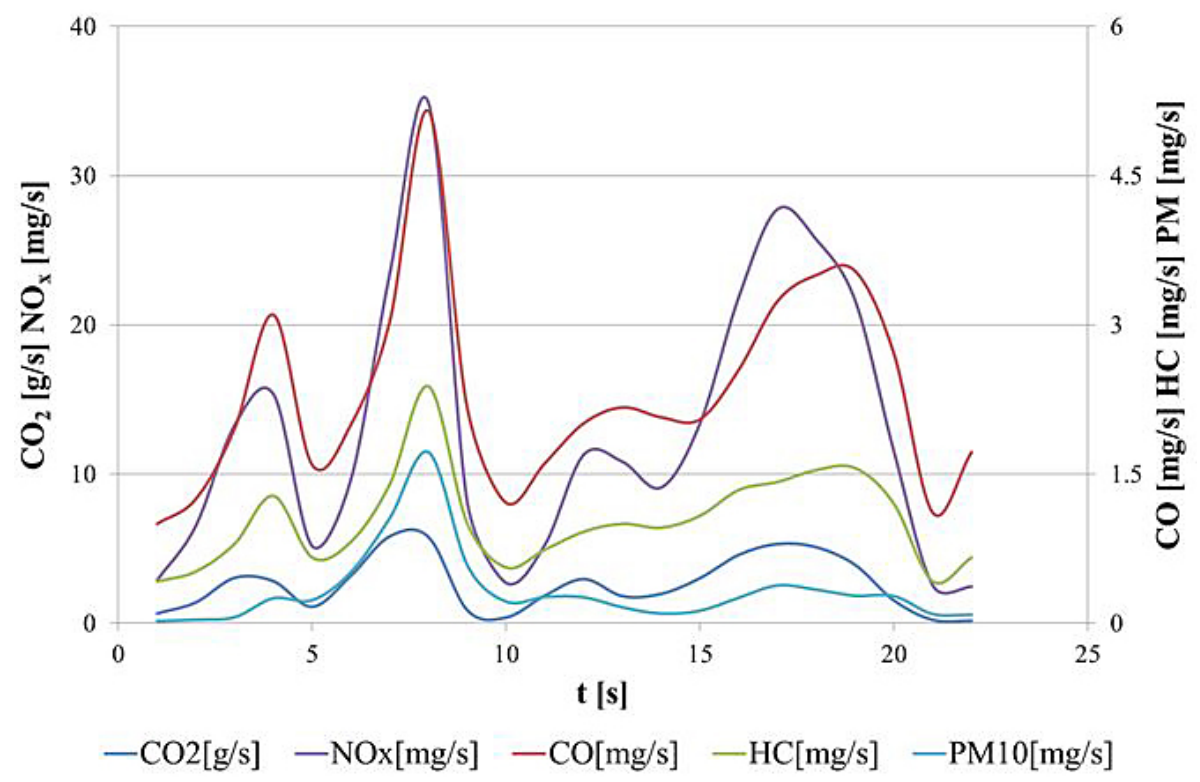

Fig. 5. Exhaust emission characteristics for an accelerating vehicle, profile I

of the test (acceleration of $1 \mathrm{~m} / \mathrm{s}^{2}$ ). The sum of these emitted compounds was: $45.6 \mathrm{~g} / \mathrm{s}$ of carbon dioxide, $13.3 \mathrm{mg} / \mathrm{s}$ of carbon oxide, $9.9 \mathrm{mg} / \mathrm{s}$ of hydrocarbons, $92.5 \mathrm{mg} / \mathrm{s}$ of nitrogen oxides and $4 \mathrm{mg} / \mathrm{s}$ of particulate matter. It follows that the first measurement with similar values of speed and acceleration of the vehicle was characterized by a much higher emission of all measured pollutants. The profile I values were higher by $20.7 \%$ $\left(\mathrm{CO}_{2}\right), 73.7 \%(\mathrm{CO}), 56.3 \%(\mathrm{HC}), 67.6 \%\left(\mathrm{NO}_{\mathrm{x}}\right)$ and $45.4 \%$ (PM) (Fig. 7).

The simulations were performed in a way that was to resemble the actual acceleration profiles of the analyzed vehicle as closely as possible. For this purpose, the simulation acceleration profile was adjusted to resemble the actual profile. In the case of the first profile, reflecting a more dynamic characteristic of the vehicle acceleration, the representation of the vehicle acceleration obtained under simulation conditions was deemed satisfactory (Fig. 8). The greatest differences could be observed for accelerating when in the first gear (first maximum acceleration), when the maximum acceleration value obtained for the simulation was approx. $10 \%$ greater than during the actual drive test. Moreover, these values lasted

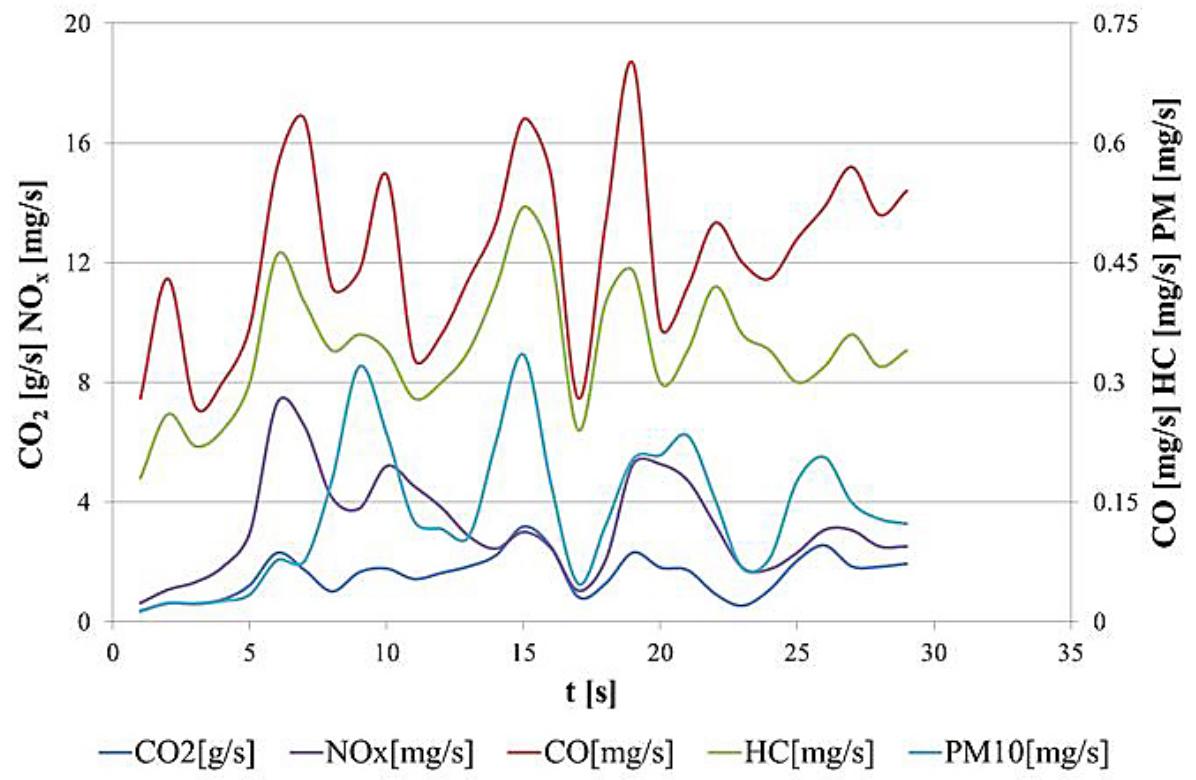

Fig. 6. Exhaust emission characteristics for an accelerating vehicle, profile II 


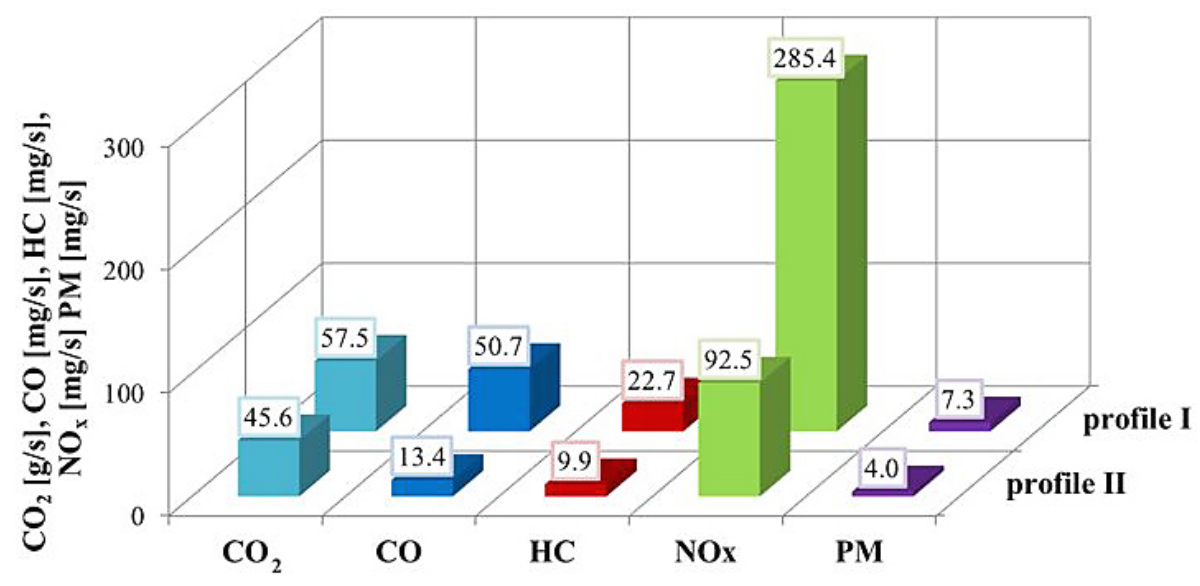

Fig. 7. Exhaust emission in time for the test drives, profiles I-II

a little longer than during the comparative road test. As a result, the vehicle acceleration profile in the simulation was slightly shifted to the right (towards higher travel speeds), but the actual acceleration values obtained during the simulation tests were very close to the values recorded in the actual driving tests.

The acceleration characteristics, modeled for the second driving profile, was mapped and reflected better than in the previous case. The obtained acceleration profiles were almost identical to those obtained in the actual tests, and only a slight shift was observed, resulting from a lower acceleration value while driving in the first gear (Fig. 9).

The $\mathrm{CO}_{2}$ emission intensity characteristics obtained in the simulation tests differ to some extent from the characteristics obtained in the actual driving acceleration tests carried out on the road.
For both the analyzed acceleration cases (profile 1 and profile 2), the simulation results show variability in similar areas as the results of the real tests, but the obtained values look averaged; the maximum values are smaller, and the minimum ones are greater (Figs. 10 and 11). The simulation test results were also more consistent with the driving phase; when the vehicle obtained higher acceleration values, the $\mathrm{CO}_{2}$ emission intensity increased (due to higher fuel consumption), whereas when the simulated vehicle acceleration value decreased, the $\mathrm{CO}_{2}$ emission intensity decreased (fuel consumption was lower).

The vehicle acceleration in road driving conditions resulted in the maximum $\mathrm{CO}_{2}$ emission intensity values reaching $6 \mathrm{~g} / \mathrm{s}$ for the first acceleration profile and approx. $3.2 \mathrm{~g} / \mathrm{s}$ for the second acceleration profile. An analogous analysis for the simulation test results led to the values of

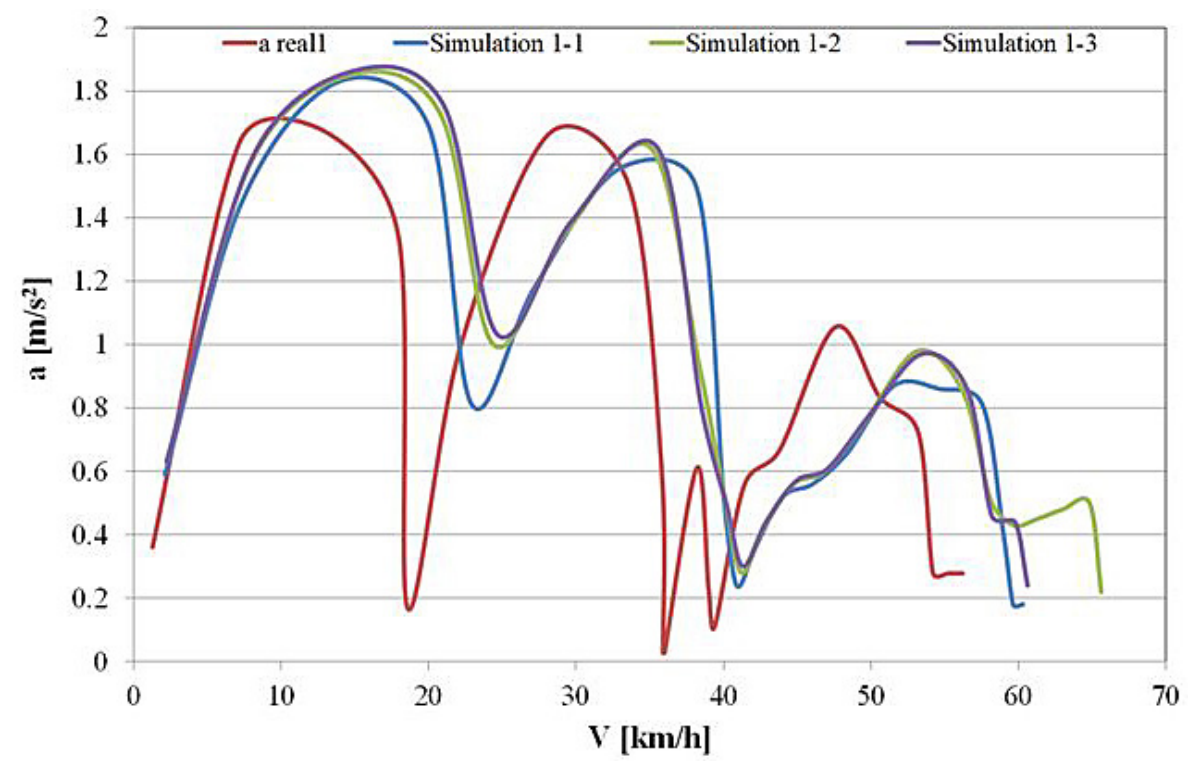

Fig. 8. Vehicle acceleration characteristics simulation, profile I 


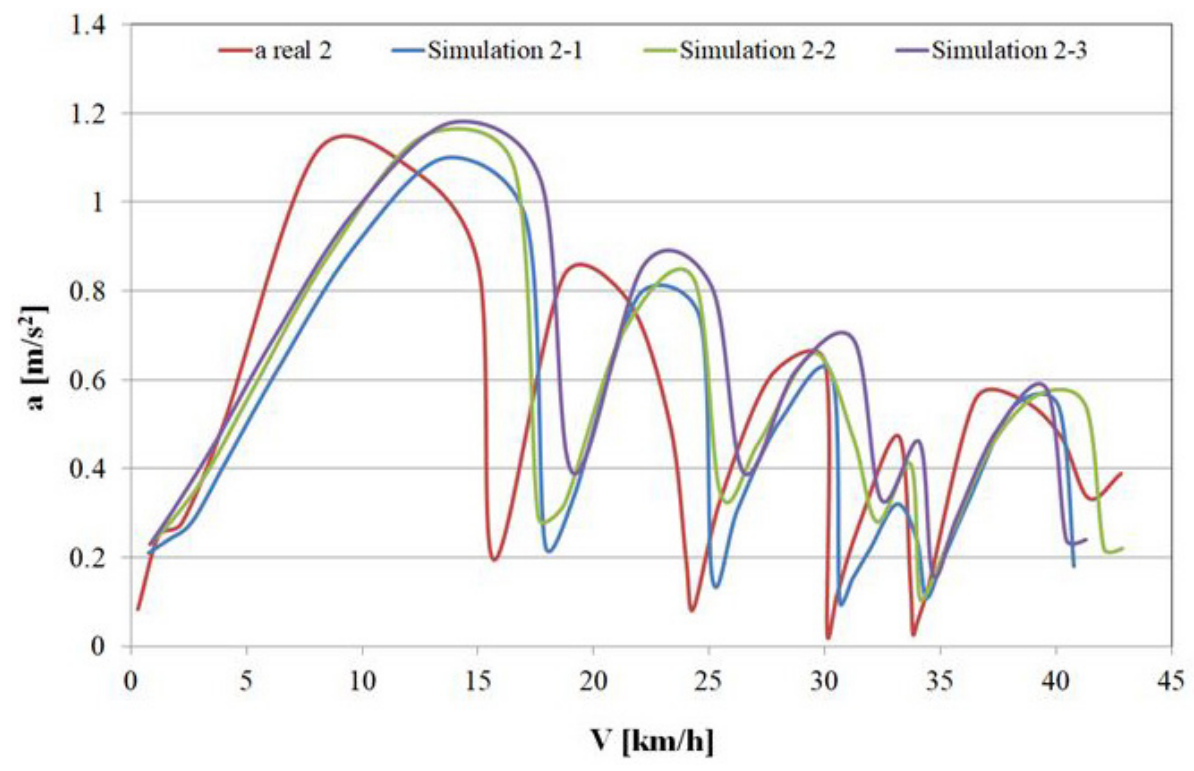

Fig. 9. Vehicle acceleration characteristics simulation, profile II

approx. $5.2 \mathrm{~g} / \mathrm{s}$ and $2.5 \mathrm{~g} / \mathrm{s}$ being recorded for the two profiles respectively. However, the maximum values obtained in the simulation were recorded at different time points of the drive in the acceleration profile than during the actual road test. An attempt to directly compare the maximum values recorded during road tests with the values obtained from the simulations at the same point on the graph (for the same vehicle speed), shows much lower values of the $\mathrm{CO}_{2}$ emission intensity observed in the simulation tests. These differences are greater for the more dynamic acceleration profile. This is certainly due to the algorithms used to run the simulation software that was employed by the authors.

While comparing the average vehicle speed values during acceleration for both profiles, it can be concluded that the simulation was carried out correctly (Fig. 12). A more dynamic acceleration (profile 1) was characterized by a mean travel speed of approx. $35 \mathrm{~km} / \mathrm{h}$. The simulations for this same profile were characterized by higher mean travel speed values, and the difference between two simulations was approx. $20 \%$, while in the case of the third simulation it was approx. $30 \%$. The acceleration of the vehicle, for the less

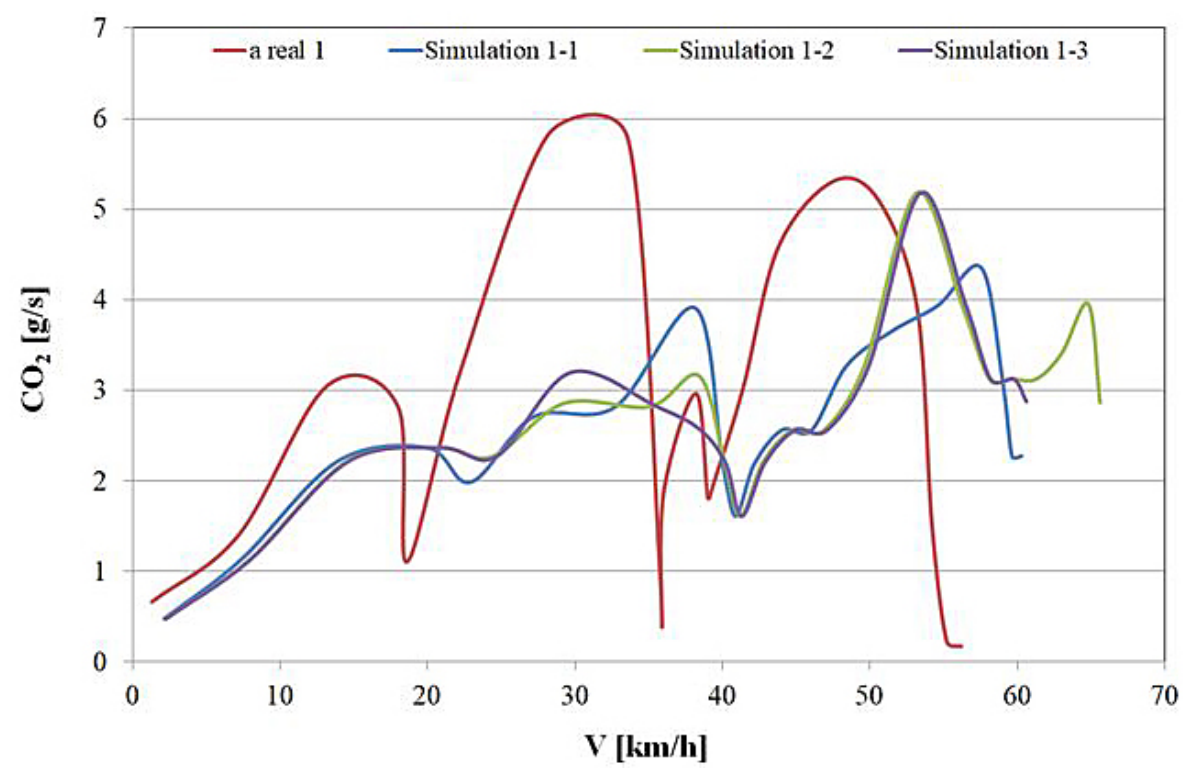

Fig. 10. Simulation of the $\mathrm{CO}_{2}$ emission characteristics during acceleration, profile I 


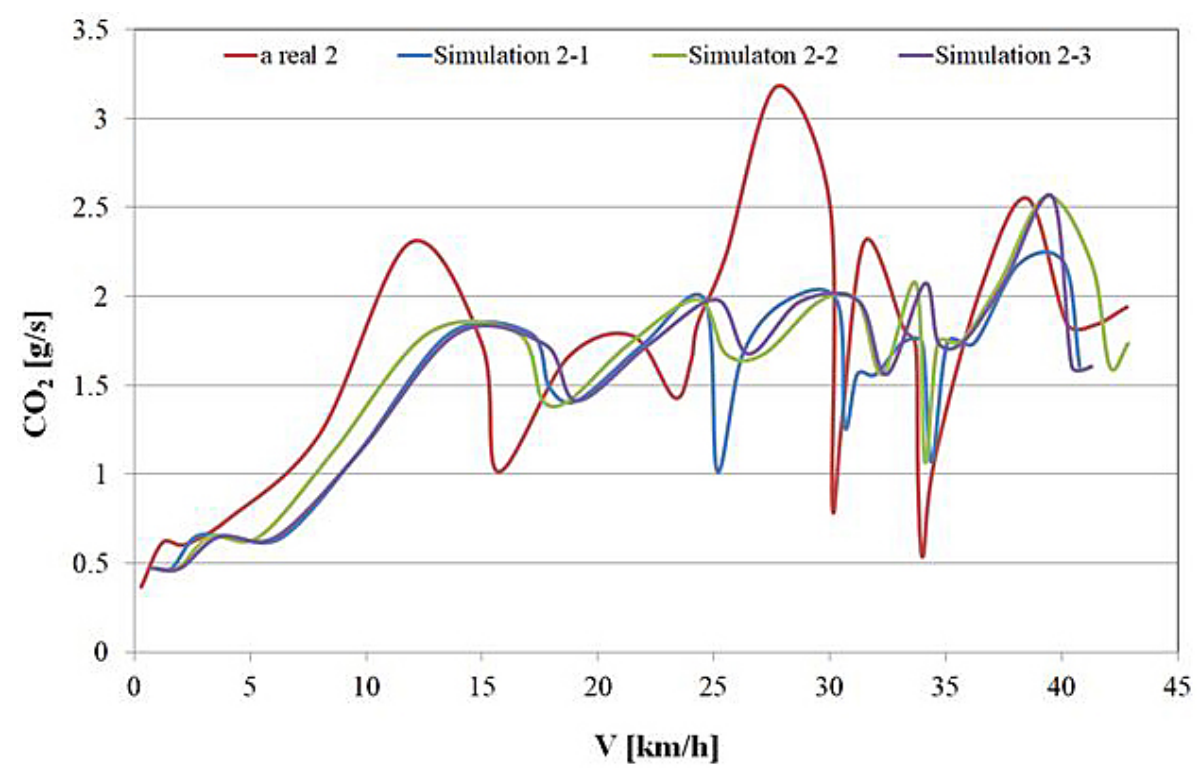

Fig. 11. Simulation of the $\mathrm{CO}_{2}$ emission characteristics during acceleration, profile II

dynamic drive (profile 2), was characterized by a mean travel speed of approx. $25 \mathrm{~km} / \mathrm{h}$. The mean speed values obtained during the simulation of this acceleration were almost identical and differ by no more than $5 \%$ compared to the actual test result, which differed more significantly.

The total $\mathrm{CO}_{2}$ emissions values for the entire vehicle acceleration phase were shown in Figure 13. The differences between the values produced during the actual driving tests and by the simulations were much smaller than in the case of the instantaneous values of the emission intensity. During the analysis of profile 1, it can be noticed that the vehicle accelerating under the actual road conditions emitted approx. $51 \mathrm{~g}$ of $\mathrm{CO}_{2}$, while the values recorded in the simulation tests were within the range of approx. 50-60 g of $\mathrm{CO}_{2}$. During acceleration when the characteristics consistent with the profile 2 was used, a greater dispersion of the results obtained by the simulation was observed (values were observed from approx. $32 \mathrm{~g} \mathrm{CO}_{2}$ to approx. $46 \mathrm{~g} \mathrm{CO}_{2}$ ) with the mass of $\mathrm{CO}_{2}$ emitted during the actual acceleration test were at the level of approx. $39.5 \mathrm{~g} \mathrm{CO}_{2}$.

The simulation software used in this research was shown to provide low accuracy in the case of the $\mathrm{CO}_{2}$ emission rates analysis (which can be related to fuel consumption) in terms of instantaneous values. However, the comparative analyses carried out confirm the legitimacy of using this software to assess the $\mathrm{CO}_{2}$ emissions for the acceleration phase of the vehicle as a whole.

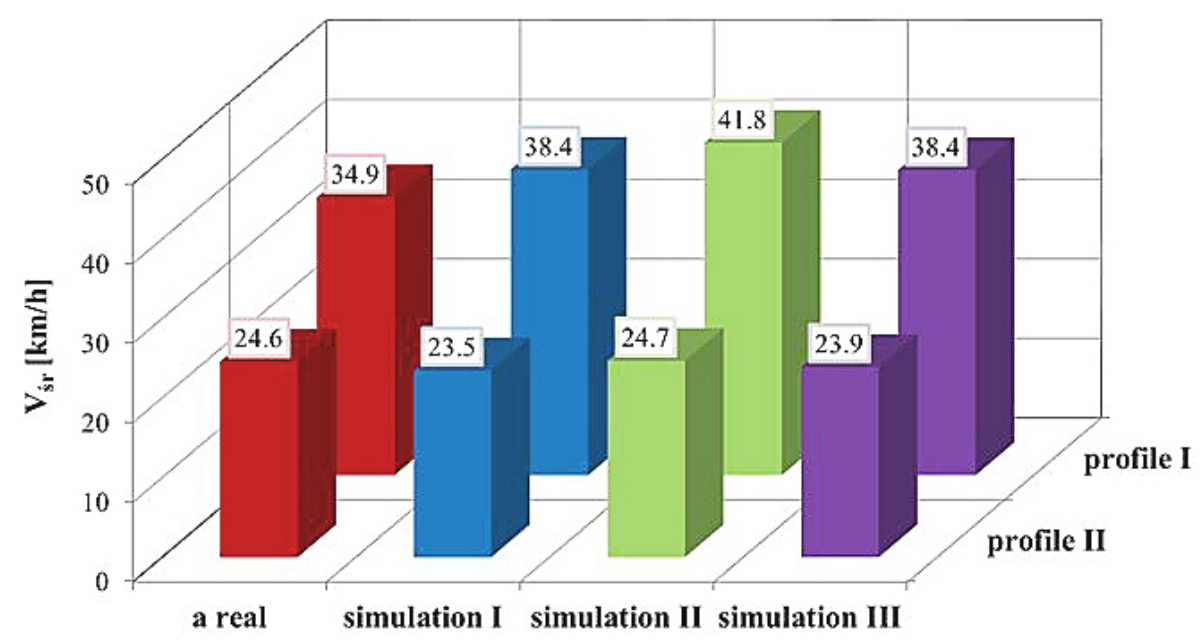

Fig. 12. Mean vehicle speed for the analyzed acceleration tests for the actual driving and simulation 


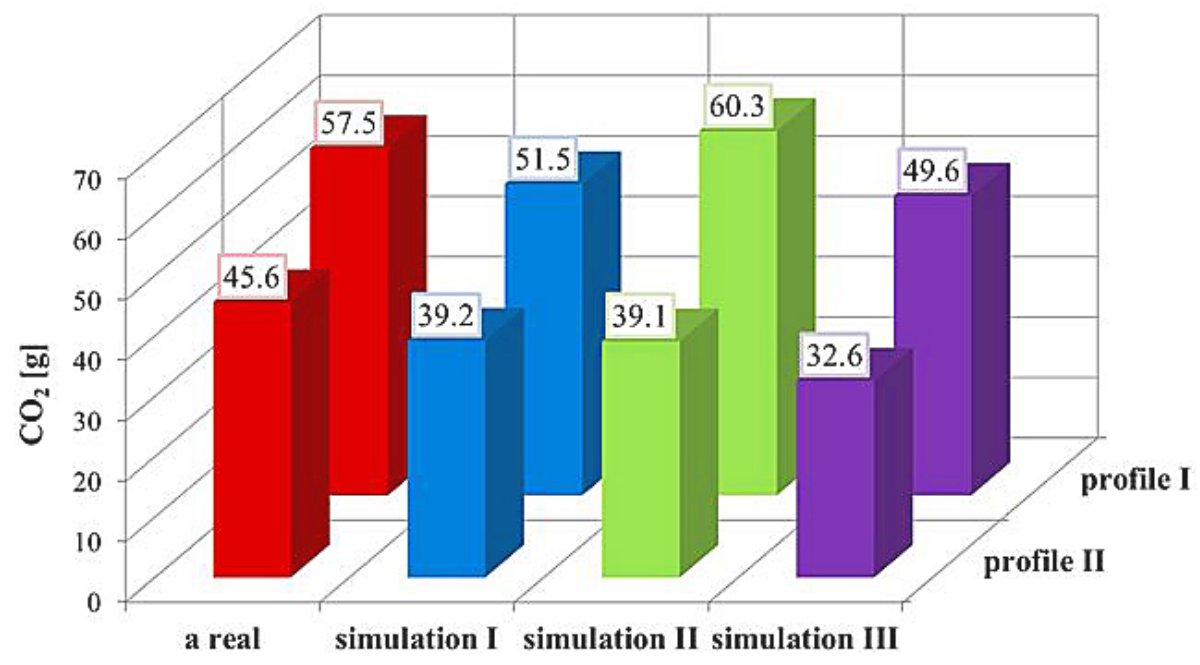

Fig. 13. Total exhaust emission of $\mathrm{CO}_{2}$ for the acceleration tests for the actual driving and simulation

\section{CONCLUSIONS}

The tests carried out under the actual operating conditions show the characteristics of exhaust emissions for two acceleration profiles of a light delivery vehicle. The obtained results show that despite the similar values of the vehicle operating parameters (speed and acceleration), during the first measurement, much higher exhaust emission values of all measured pollutants were achieved. In the case of profile I, a strong dependence of $\mathrm{CO}_{2}, \mathrm{CO}, \mathrm{HC}, \mathrm{NO}_{\mathrm{x}}$ and $\mathrm{PM}$ on the instantaneous acceleration values could be observed. In the case of profile II, however, such a correlation could not be clearly observed. Measurement I was performed while driving in gears 1 and 2, while in test drive profile II the driver of the vehicle changed gears from 1 to 4 , which can be easily observed on the vehicle acceleration characteristics. This means that despite having similar values of the main vehicle operating parameters, the engine operating parameters still differed significantly. Higher values of engine rotational speed and load achieved during measurement I contributed to the emission of more harmful exhaust compounds. On the basis of these studies, simulations were then created to reproduce the actual acceleration profiles obtained for the analyzed vehicle.

Despite slight deviations in the speed profile characteristics in the simulation tests, the obtained results allowed concluding that this method was useful in mapping vehicle acceleration. However, it should be added that the results of $\mathrm{CO}_{2}$ emissions (which also reflect fuel consumption) obtained with the use of simulation software should be analyzed with some caution.
This relates mainly to the instantaneous values of the $\mathrm{CO}_{2}$ emissions intensity which, compared to the results obtained during the road acceleration tests, were characterized by much lower variability. It was concluded that these instantaneous values were still highly averaged - the maximum values were smaller and the minimum values were greater than during the actual road tests. In the case of the total exhaust emission values for the entire analyzed vehicle acceleration profiles, the differences obtained from the simulation tests for the first profile were greater by less than $20 \%$ compared to the results of the road tests, while the differences obtained for the profile 2 ranged from $-19 \%$ to $+16 \%$. Such differences should be considered acceptable and, according to the authors, there is a chance to reduce them by even better mapping of the actual acceleration tests.

In future work, it would be reasonable to carry out this type of acceleration analysis for cars powered by spark ignition engines as well as for vehicles adhering to other emission norms. This would make it possible to confirm the validity of using the simulation methods in the energy consumption assessment of vehicles powered by various generations of internal combustion engines.

\section{Acknowledgments:}

The research was funded by European Union from European Regional Development Fund through the National Centre for Research and Development (Narodowe Centrum Badań i Rozwoju) - research project within the Smart Growth Programme (contract No. POIR.04.01.02-00-0002/18). 


\section{REFERENCES}

1. Abou-Senna H., Radwan E., Westerlund K., Cooper C.D. 2013. Using a traffic simulation model (VISSIM) with an emissions model (MOVES) to predict emissions from vehicles on a limited-access highway. Journal of the Air \& Waste Management Association, 63(7), 819-831.

2. Csikós A. \& Varga I. 2012. Real-time modeling and control objective analysis of motorway emissions. Procedia-Social and Behavioral Sciences, 54, 1027-1036.

3. Maciejewski M. 2010. A comparison of microscopic traffic flow simulation systems for an urban area. Transport Problems, 5, 27-38.

4. Madi M.Y. 2016. Investigating and calibrating the dynamics of vehicles in traffic micro-simulations models. Transportation Research Procedia, 14, 1782-1789.

5. Mądziel M., Campisi T., Jaworski A., Tesoriere G. 2021. The Development of Strategies to Reduce Exhaust Emissions from Passenger Cars in Rzeszow City-Poland. A Preliminary Assessment of the Results Produced by the Increase of E-Fleet. Energies, 14(4), 1046, 1-21.

6. Merkisz J., Mizera J., Bajerlein M., Rymaniak L., Maj P. 2014. The Influence of Laser Treatment and the Application of Reduced Pressure Force Piston Rings on the Engine Exhaust Emissions under the Conditions of Engine Lubrication with Different Engine Oils. Applied Mechanics and Materials, 518, 102-107.
7. Merkisz J., Pielecha J., Fuc P., Lijewski P. 2012. The analysis of the PEMS measurements of the exhaust emissions from city buses using different research procedures. IEEE Vehicle Power and Propulsion Conference, 903-907.

8. Nowak M., Andrzejewski M., Galant M., Rymaniak Ł. 2019. Simulation assessment of the selected combination of road and rail infrastructure in the aspect of choosing the route of road transport means. AIP Conference Proceedings, 2078(1), 1-6.

9. Nowak M. \& Pielecha J. 2017. Comparison of exhaust emission on the basis of Real Driving Emissions measurements and simulations. MATEC Web of Conferences. 118(00026), 1-8.

10. Rymaniak L., Daszkiewicz P., Merkisz J., Bolzhelarskyi Y.V. 2019. Method of determining the locomotive engine specific fuel consumption based on its operating conditions. AIP Conference Proceedings, 2078(1), 1-8.

11. Rymaniak L. 2017. Comparison of the combustion engine operating parameters and the ecological indicators of an urban bus in dynamic type approval tests and in actual operating conditions. MATEC Web of Conferences. 118(00009), 1-9.

12. Szymlet N., Lijewski P., Kurc B. 2020. Road Tests of a Two-Wheeled Vehicle with the Use of Various Urban Road Infrastructure Solutions. Journal of Ecological Engineering, 21(7), 152-159.

13. www.drogi.gddkia.gov.pl

14. www.europarl.europa.eu

15. www.globalmrv.com

16. www.gpsvisualizer.com 